\title{
Prevalence and changing distribution of HTLV-1 and HTLV-2 infections in Spain
}

\author{
Ana Treviño ${ }^{1 *}$, Antonio Aguilera ${ }^{2}$, Estrella Caballero ${ }^{3}$, Rafael Benito $^{4}$, Patricia Parra ${ }^{1}$, Jose M Eiros ${ }^{5}$, \\ Araceli Hernandez ${ }^{6}$, Enrique Calderón ${ }^{7}$, Manuel Rodríguez ${ }^{8}$, Alvaro Torres ${ }^{9}$, Juan García ${ }^{10}$, Jose Manuel Ramos ${ }^{11}$, \\ Lourdes Roc ${ }^{12}$, Goitzane Marcaida ${ }^{13}$, Carmen Rodríguez ${ }^{14}$, Matilde Trigo ${ }^{15}$, Cesar Gomez ${ }^{16,17}$, \\ Raul Ortíz de Lejarazu ${ }^{5}$, Carmen de Mendoza', Vincent Soriano ${ }^{1}$
}

From 15th International Conference on Human Retroviruses: HTLV and Related Viruses

Leuven and Gembloux, Belgium. 5-8 June 2011

\section{Background}

Most HTLV-1/2 infections in Spain have been found in native intravenous drug users carrying HTLV-2. However, the large immigration flows from Latin America and Africa during the last decade may have changed the prevalence and distribution of HTLV-1 and HTLV-2 infections, and hypothetically even open the opportunity for introducing the new HTLV-3 or HTLV-4 variants.

\section{Methods}

A national multicenter, cross-sectional, national study was conducted in June 2009 recruiting consecutive adult outpatients attending 16 different hospitals in Spain. HTLV-1/2 antibodies were screened using an EIA and further confirmed using a commercial Western blot. Samples with indeterminate Western blot patterns were examined using specific PCR assays for discriminating HTLV types 1 to 4 .

\section{Resuts}

A total of 6,460 patients were studied. Overall, $40 \%$ were males and $88 \%$ were native Spaniards. The main origin of the immigrant population was Latin America (4.9\%), Africa (3.6\%) and other European countries (2.8\%). A total of 9 individuals were seroreactive for HTLV antibodies (overall prevalence $0.14 \%$ ). Of these, Western blot confirmed as HTLV-1 in 4 (prevalence $0.06 \%$ ) and HTLV-2 in 5 (prevalence $0.08 \%$ ). Another 2 specimens yielded EIA reactivity close to the cut-off and could not

\footnotetext{
* Correspondence: ana.trevino.rc@gmail.com

${ }^{1}$ Hospital Carlos III, Madrid, Spain

Full list of author information is available at the end of the article
}

be confirmed as positive for any of the HTLV types 1 to 4. All but one HTLV-1 cases were Latin Americans while all HTLV-2 cases were native Spaniards. The single HTLV-1 subject born in Spain was a 31 year-old woman who denied any significant risk behavior for HTLV exposure, including intravenous drug use, sexual promiscuity, transfusions or travel to Latin America. All HTLV-1 carriers but one were asymptomatic. A woman from the Dominican Republic was diagnosed with mild TSP/HAM.

\section{Conclusions}

The overall prevalence of HTLV-1/2 infections in Spain remains low, although a shift in the relative proportion of HTLV-1 and HTLV-2 seems to have occurred in recent years. The recognition of HTLV-1 in a native Spaniard with lack of recognizable risk factors for HTLV-1 exposure should alert about a spread of HTLV-1 outside classical risk groups. No cases of HTLV-3 nor HTLV-4 infections have been identified so far in Spain.

\footnotetext{
Author details

${ }^{1}$ Hospital Carlos III, Madrid, Spain. ${ }^{2}$ Hospital Conxo, Santiago de Compostela, Spain. ${ }^{3}$ Hospital Vall dÂ`Hebron, Barcelona, Spain. ${ }^{4}$ Hospital Clínico Universitario Lozano Blesa, Zaragoza, Spain. ${ }^{5}$ Hospital Clínico Universitario, Valladolid, Spain. ${ }^{6}$ Hospital Insular, Las Palmas de Gran Canaria, Spain. ${ }^{7}$ Hospital Universitario Virgen del Rocío, Seville, Spain. ${ }^{8}$ Hospital Universitario Puerta del Mar, Cádiz, Spain. ${ }^{9}$ Hospital Universitario de Canarias, Santa Cruz de Tenerife, Spain. ${ }^{10}$ Hospital Cristal-Piñor, Orense, Spain. ${ }^{11}$ Hospital General, Elche, Spain. ${ }^{12}$ Hospital Miguel Servet, Zaragoza, Spain. ${ }^{13}$ Hospital General Universitario, Valencia, Spain. ${ }^{14}$ Centro Sanitario Sandoval, Madrid, Spain. ${ }^{15} \mathrm{Complejo}$ Hospitalario, Pontevedra, Spain. ${ }^{16} \mathrm{Complejo}$ Hospitalario Virgen de la Salud, Toledo, Spain. ${ }^{17}$ ana.trevino.rc@gmail.com.
} 
Submit your next manuscript to BioMed Central and take full advantage of:

- Convenient online submission

- Thorough peer review

- No space constraints or color figure charges

- Immediate publication on acceptance

- Inclusion in PubMed, CAS, Scopus and Google Scholar

- Research which is freely available for redistribution 